Agriculture and Food Sciences Research

Vol. 6, No 2, 155-165, 2019

$\operatorname{ISSN}(E)$ 2411-6653/ISSN(P) 2518-0193

DOI: $10.20448 /$ journal.512.2019.62.155.165

(C) 2019 by the authors; licensee Asian Online Journal Publishing Group

Check for
updates

\title{
Measuring the Climate Variability Impact on Cash Crops Farming in India: An Empirical Investigation
}

\section{Ajay Kumar Singh ${ }^{\rtimes}$ Bhim Jyoti ${ }^{2}$}

Assistant Professor (Economics), Department of Humanities and Social Sciences, DIT University, Dehradun, Uttarakhand-248009, India

Email: a.k.seeku@gmail.com

Assistant Professor (Seed Science and Technology), V.C.S.G., UUHF, College of Forestry, Ranichauri, Tehri Garhwal. Uttarakhand, India

Email:bhimjvoti.2210@gmail.com

\section{Abstract}

This study investigates the climate variability impact on potato, cotton, groundnut and sesame crops in Indian states. Thereupon, it estimates the technical efficiency (TE) of climatic and nonclimatic factors in crops farming in Indian states during 1971-2014. Production, yield and area sown of aforementioned crops are considered as dependent variables and regressed with socioeconomic and climatic variables using state-wise panel data employing C-D PFM. Sates-wise TE of cash crops is estimated using SFPFM under non-parametric condition. Estimates indicate that climate variability show negative impact on production, yield and area sown of aforesaid cash crops. Thus, it is essential to adopt effective policy to mitigate the negative consequences of climate variability in cash crop farming in India. Cropped area, production and yield of cash crops are negatively impacted due to climatic variability in India. So there needs to adopt crop specific policies to mitigate the negative impact of climate variability in cash crop farming. Finally, it estimates the technical efficiency (TE) of cash crop using SFPFM across Indian states. Estimated values of TE for production, yield and area sown of associated crops imply that there is significant variation in TE due to climate variability and huge diversity in socio-economic characteristic across Indian states. Thus, most of states have potential opportunity to increase production and yield of cash crops through enlightening technical efficiency of inputs in cultivation.

Keywords: Commercial crops, Yield, Production, Cropped area, Technical efficiency, SFPFA, C-D PFM, Climate change.

Citation | Ajay Kumar Singh; Bhim Jyoti (2019). Measuring the Climate Variability Impact on Cash Crops Farming in India: An Empirical Investigation. Agriculture and Food Sciences Research, 6(2): 155-165.

History:

Received: 25 March 2019

Revised: 2 May 2019

Accepted: 6 June 2019

Published: 18 July 2019

Licensed: This work is licensed under a Creative Commons

Attribution 3.0 License (cc)

Publisher: Asian Online Journal Publishing Group
Acknowledgement: Both authors contributed to the conception and design of the study.

Funding: This study received no specific financial support.

Competing Interests: The authors declare that they have no conflict of interests.

Transparency: The authors confirm that the manuscript is an honest, accurate, and transparent account of the study was reported; that no vital features of the study have been omitted; and that any discrepancies from the features of the study have been omitted;
study as planned have been explained.

Ethical: This study follows all ethical practices during writing.

\section{Contents}

1. Background .

2. Climate Sensitivity and Cash Crops Farming.

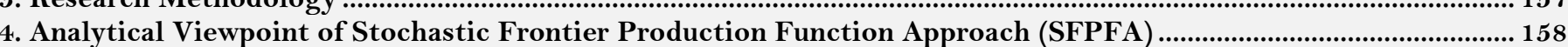

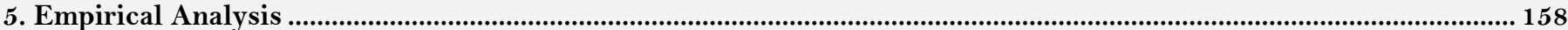

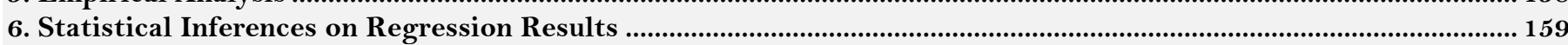

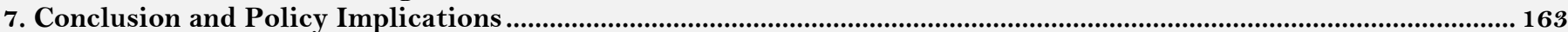

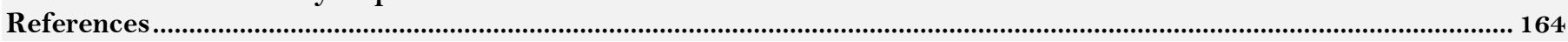




\section{Contribution of this paper to the literature}

The study contributes to the existing literature by estimating the technical efficiency of production, yield and area sown of major cash crops across Indian states.

\section{Background}

Agriculture is the backbone for Indian economy and it is prime source to sustain food security and raw material for various industries like textile, oilseed, sugar and other industries. Indian agriculture is highly vulnerable due to climate change. In this context, numerous of studies have assessed the impact of climate change on yield and production of food-grain and cash crops in different regions/states in India [1-11]. In brief: Singh, et al. [12]; Kumar and Sharma [1]; Ayyogari, et al. [13]; Kumar, et al. [6]; Kumar, et al. [14]; Yadav, et al. [15]; Singh, et al. [9] have investigated the impact of climate change on potato yield, Hundal and Kaur [16]; Ashalatha, et al. [17]; Kumar and Sharma [18]; Kumar and Sharma [1]; Birthal, et al. [19]; Kumar, et al. [14]; Yadav, et al. [15]; Singh, et al. [9]; Ramachandran, et al. [11] have assessed the climate change impact on groundnut yield, Nath, et al. [20]; Kumar and Sharma [1]; Kumar, et al. [14]; Singh, et al. [9] have observed the climate change impact on sesame productivity, and Masters, et al. [21]; Sankaranarayanan, et al. [22]; Moorthy, et al. [23]; Deshmukh and Lunge [24]; Ashalatha, et al. [17]; Kumar and Sharma [1]; Hebbar, et al. [2]; Raju, et al. [25]; Thakare, et al. [26]; Kumar, et al. [14]; Singh, et al. [9] have explored the climate change impact on cotton crop productivity in India. Descriptive and empirical results of aforesaid studies were based on time series and district-wise/state-wise panel data, which were included crop productivity as a dependent variable. Few studies have incorporated per hectare output (in monetary) of a cash crop as a dependent variable and it was regressed with climatic and nonclimatic factors using district-wise/state-wise panel data in India [7, 9, 10, 14, 19, 27].

Most researchers have used agricultural production per hectare land (in monetary) of selected food-grain and cash crops as dependent variables, which was regressed with climatic and non-climatic factors using state-wise panel data in India $[3,4,6,10,14,27,28]$. Few studies have segregated the agricultural productivity (in monetary) of Rabi and Kharif crops to assess the impact of climate change on it using state-wise and district-wise panel data in India [1, 4-6, 10, 27]. Earlier studies have provided empirical evidence that climate change have a negative and significant impact on productivity of cash crops in India. Agricultural productivity is also negatively impacted due to climate change in India $[1,5,6,27,28]$. However, limited studies assessed the impact of climate variability on all aspects (i.e., cropped area, production and yield) of cash crops farming in India. Existing researchers also could not estimate the technical efficiency $(T E)$ of climatic and non-climatic factors in cash crop farming in India. It would be useful to formulate crop specific policy to increase the $T E$ of inputs in cash crop farming. Most studies clearly indicate that agricultural productivity or net revenue of most cash crops decrease due to climate change in different regions of India. Most studies analyzed the climate change impact on agricultural productivity or net revenue of cash crops for a particular regions of India. Therefore, the present study address the few research questions which are given as:

- How climate variability does affect area sown, production and yield of cash crops in different periods of crops in India?

- Is technical efficiency of cash crop farming varied across Indian states?

- Is possible to mitigate the adverse effective of climate variability in cash crop farming in India?

Relevance to aforementioned research questions, the present study is achieved following objectives:

- To investigate the impact of climate variability on various cash crops (i.e., Potato, Cotton, Groundnut and Sesame) in India.

- To estimate the $T E$ of climatic and non-climatic factors in cash crops farming across Indian states.

- To provide the conclusive policy implications to mitigate the adverse effects of climate change in cash crop faming.

\section{Climate Sensitivity and Cash Crops Farming}

It is observed that productivity of cash and food-grain crops are negatively impacting due to variability in minimum temperature, maximum temperature and change in rainfall pattern in India Ayyogari, et al. [13]; Yadav, et al. [15]. Hijmans [29] detected that potato yield decreases by $18 \%$ to $32 \%$ as temperature increases by 1 to $1.4^{\circ} \mathrm{C}$ respectively in potato producing economies. Furthermore, potato yield is expected to be increased in Algeria, China, Morocco and South Africa [29]. Potato crop is passing through various physiological processes during sowing, growing and harvesting time [13]. Hence, variability in climatic factors have a negative impact on potato growth and yield [12-15, 29].

Hundal and Kaur [16] estimated that groundnut yield is likely to be declined by $23.2 \%$ and $36.2 \%$ as temperature increases by 1.2 and $3^{\circ} \mathrm{C}$ respectively in Punjab (India). Nath, et al. [20] investigated the impact of climatic variations on sesame productivity during sowing time in Kalyani (India). It shows that climate variability during various days in sowing time have a negative impact on sesame yield and the effect of climate variability on sesame yield varies across days. Masters, et al. [21] reported that growing season of cotton crop increases in moderate temperature, thus cotton yield would be improved. The study show that climate change would have a negative impact on cotton yield in near future. Sankaranarayanan, et al. [22] also reviewed that climatic factors have a negative impact on production and yield of cotton crop in India.

Deshmukh and Lunge [24] explored that association of maximum and minimum temperatures and rainfall with cotton yield in Vidarbha (Maharashtra) India. It found that climatic factors have a significant impact on cotton yield. Moorthy, et al. [23] projected the effect of historical climate change on yield of cotton, sugarcane, rice, wheat and sorghum crops. It shows that temperature and precipitation did show insignificant impact on yields of cotton, while climate factors have a non-linear relationship with it. Ashalatha, et al. [17] analyzed the drought effect on crop yield and farmer's understanding towards climate change in Dharwad Karnataka (India). It observed that groundnut and cotton yields decreases by 34.09 and $59.96 \mathrm{Kg} / \mathrm{Ha}$ respectively in rainfed areas due to low rainfall. 
Kumar and Sharma [1] observed that yield of cotton and sesame crops were negatively associated with maximum temperature, while yields of potato and linseed crops are expected to be declined as increase in minimum temperature in India. Hebbar, et al. [2] assessed the climate change impact on cotton yield in different climate change scenarios (i.e., A2, B2 and A1B). It reported that cotton yield has a probability to be declined by $477 \mathrm{Kg} / \mathrm{Ha}$ and $268 \mathrm{Kg} / \mathrm{Ha}$ under $\mathrm{A} 2$ and $\mathrm{B} 2$ scenario respectively, while cotton yield was statistically in-significant under A1B scenario. Singh, et al. [12] attain the farmer's understanding on climate change and assess the climatic impact on cotton yield and production in Rajasthan, Andhra Pradesh and Maharashtra. This study concluded that climate change have a negative impact on cotton yield, water quality and fabric quality.

Singh, et al. [30] examined the impact of climate change on groundnut yield in Anantapur and Mahboobnagar districts of Andhra Pradesh and Junagadh districts of Gujarat in India. Results of the study based on CROPGROGroundnut model indicate that groundnut yield decreases as increase in temperature. However, the effects of temperature, rainfall and $\mathrm{CO}_{2}$ emissions on groundnut yield would vary in aforementioned districts. Thakare, et al. [26] assessed the variability in cotton yield due to change in rainfall pattern, and maximum and minimum temperature in Surat district of Gujarat in India. It found that rainfall variability has a negative impact on crop physiology and cotton yield. Raju, et al. [25] measured the impact of temperature and rainfall on cotton yield in Andhra Pradesh (India). It point out that cotton yield decreases by $13 \mathrm{Kg} / \mathrm{Ha}$ and $0.7 \mathrm{Kg} / \mathrm{Ha}$ as increase in $1^{\circ} \mathrm{C}$ maximum temperature and $10 \mathrm{~mm}$ rainfall respectively. Birthal, et al. [19] explored the variability in climatic factors (i.e., temperature and rainfall) during 1969-2005 and climate impact on yield of food-grain crops in India. It observed that groundnut yield decreases by $9 \%$ as $1^{\circ} \mathrm{C}$ increase in maximum temperature, while minimum temperature and rainfall showed a positively impact on groundnut yield. However, rainfall could not compensate the reduction in groundnut yield due to increase in maximum temperature.

Kumar, et al. [14] examined the climate change impact on mean yield and yield variability of cotton, groundnut, potato, sesame and linseed crops using stochastic production function approach in India. It observed that mean yield of cotton and sesame crops are likely to be declined by $2.03 \%$ and $2.80 \%$ respectively as $1{ }^{\circ} \mathrm{C}$ increase in maximum temperature. Productivity of potato and linseed may be declined by $0.47 \%$ and $0.84 \%$ respectively due to $1^{\circ} \mathrm{C}$ increase in minimum temperature. Singh, et al. [9] evaluated the impact of climatic and non-climatic factors on cropped area, yield and production of cash crops across Indian states. It observed that cropped area under groundnut and sesame crops decrease by $13.87 \%$ and $23.50 \%$ respectively, while groundnut and cotton production declines by $9.83 \%$ and $41.09 \%$ respectively; and productivity of potato, groundnut, sesame and cotton crops declines by $3.71 \%, 10.31 \%, 4.51 \%$ and $7.20 \%$ respectively due to $1 \%$ variability in climatic factors. Ramachandran, et al. [11] reported that productivity of potato and groundnut crops are expected to be declined by $3-7 \%$ as increase in $1^{\circ} \mathrm{C}$ temperature in India.

\section{Research Methodology}

\subsection{Introduction of Study Area}

Separate state-wise panel data (during 1971-2014) was compiled for potato, cotton and groundnut crops from fifteen states of the country Refer Table 1. Climatic and non-climatic factors are considered in this analysis.

Table-1. Detail of crops which are included in each state-wise panel.

\begin{tabular}{c|l}
\hline Name of States & Name of crops undertaken from respective states \\
\hline Andhra Pradesh & Potato, Cotton, Groundnut, Sesame \\
\hline Assam & Potato, Cotton, Sesame \\
\hline Bihar & Potato, Cotton, Groundnut, Sesame \\
\hline Gujarat & Potato, Cotton, Groundnut, Sesame \\
\hline Haryana & Potato, Cotton, Groundnut, Sesame \\
\hline Karnataka & Potato, Cotton, Groundnut, Sesame \\
\hline Kadhya Pradesh & Cotton, Groundnut, Sesame \\
\hline Maharashtra & Potato, Cotton, Groundnut, Sesame \\
\hline Odisha & Potato, Cotton, Groundnut, Sesame \\
\hline Punjab & Potato, Cotton, Groundnut, Sesame \\
\hline Rajasthan & Potato, Cotton, Groundnut, Sesame \\
\hline Tamil Nadu & Potato, Cotton, Groundnut, Sesame \\
\hline Uttar Pradesh & Potato, Cotton, Groundnut, Sesame \\
\hline West Bengal & Potato, Cotton, Groundnut, Sesame \\
\hline Source: Author's compilation based on undertaken data of different states for this study, Sesame
\end{tabular}

Source: Author's compilation based on undertaken data of different states for this study.

\subsection{Description on Data Sources}

Information on production, yield, area sown, irrigated area and consumption of fertilizer for each crop are derived from Centre for Monitoring Indian Economy (CMIE). Forest area is also taken from CMIE. Value of production of each crop is estimated at farm harvest prices with constant level as 1993-94 base year. Farm harvest price of cash crop is taken from the different publications of Directorate of Economics and Statistics Department of Agriculture, Cooperation and Farmers Welfare, Ministry of Agriculture (GoI). Agricultural labour and cultivators are taken from the different publication of Census (GoI), which is available in decadal periods (i.e. 1971, 1981, 1991, 2001 and 2011). Rural literate population is taken from the Planning Commission (GoI), which is available aforesaid periods. Minimum temperature, maximum temperature and precipitation related data are derived from the Indian Meteorological Department (IMD) (GoI) database, Geographic Information System and official website of Indian Institute of Tropical Meteorology, New Delhi. Climatic data is available on daily intervals with latitude and longitude information of monitoring stations. So, city-wise geographical locations or stations are identified to derive the data on climatic factors for all cities in a state. Thereafter, groups of different geographical location in a state is integrated to arrive at state-wise data $[8,9]$. Thence, these data are converted in monthly averages citywise, after that data is transformed in state-wise monthly maximum temperature, minimum temperature and 
precipitation [9]. Aforesaid process is done through the $\mathrm{C}^{++}$statistical software, while SPSS statistical software is used to extract and bring data to excel format. Minimum temperature, maximum temperature and precipitation in three growth periods i.e., sowing time, growing time and harvesting time of each crop is integrated in regression models [8-10]. Interpolation and extrapolation techniques are used to fill the missing values to complete the time series during 1971-2014 in each state-wise panel data [1, 3, 4, 6-10,14].

\section{Analytical Viewpoint of Stochastic Frontier Production Function Approach (SFPFA)}

Existing researchers have used SFPFA to explore the effect of climatic and non-climatic factors on crop productivity and to estimate the technical efficiency (TE) in agricultural production analysis in different economies [31-37]. SFPFA model can be applied in parametric and non-parametric condition [34, 36, 37]. It comprises parameters of production and inefficiency function simultaneously in a model [38]. So, in this study SFPFA model is applied to investigate the TE of cash crops farming. Production, yield and area sown of cash crops are considered as dependent variables and recursively regressed with climatic and non-climatic factors [5]. Cobb-Douglas production function model is used to estimate the regression coefficients of climatic and non-climatic variables in empirical models [4, 14].

It is observed that crop productivity and production are significantly associated with variability in climatic and non-climatic factors $[1-11,17,21,23,24]$. Thus, the SFPFA model assumes that variability in climate factors have a significant association with production efficiency of crops [39]. Climate change have a negative impact on technical efficiency of production, yield and cropped area in crop farming [39]. TE of a production unit can be measured through SFPFA [31-37]. In the present study SFPFA approach is used, which comprises two terms: non-negative and systematic distribution. It may be presented in following functional forms [34, 36, 37]:

$$
Y_{i}=f\left(X_{s,}, \beta\right) \exp \left(e_{s i}\right)
$$

Here, Yi is the production or productivity of each crop, Xit is the vector of independent variables; $\beta$ is the vector of regression coefficients of associated explanatory variables; and $e_{s t}$ is the error term in Equation 1.

$$
\Upsilon_{i}=f\left(X_{s,} \beta\right) \exp \left(v_{s t}-u_{s t}\right)
$$

Here, $Y_{s t}$ is the output of a specific crop in state $(s)$ in year $(t) ; X$ is vector of climatic and non-climatic variables; $\beta$ is the vector of regression coefficients of explanatory variables [36, 37]; $e_{s t}\left(=v_{s t}-u_{s t}\right)$ is random error term that includes $u_{s}$ and $v_{s t}$ in Equation 2. It is identically and normally distributed $\left[N\left(O, \sigma^{2}\right)\right]$ term [36, 37]. $u_{s t}$ may be considered truncated-normal distribution with zero mean $(\mu)$ with constant variance $\left(\sigma^{2}\right)$ while $u_{*}$ and $v_{* t}$ are also normally distributed for different states [38]. SFPFA model may be used in terms of time-invariant and timevarying models. This study is used time-invariant model to assess the regression coefficients of variables and to estimate TE.

Assessment of Technical Efficiency (TE): TE of a state can be estimated using following formula [38]:

$$
T E_{s t}=\exp \left(-u_{s}\right)
$$

Here, $T E_{s t}$ is the technical efficiency of a state, and $u_{s}$ is estimated through Equation 3. If the value of TE of a states is equal to 1 then it can be concluded that the state has no technical inefficiency in crop production [38].

\section{Empirical Analysis}

\subsection{Creation of Empirical Model for Crop Farming}

Log-linear (Cobb-Douglas) (C-D) production function model is considered to measure the impact of climate and non-climatic on production of undertaken crops. For this, total production of crops are used as dependent variables and regressed with climatic and non-climatic factors under the SFPFA. Following functional form of empirical model is applied $[9,40]$ :

$\ln (t p)_{s t}=\beta_{o}+\beta_{1} \ln (a s)_{s t}+\beta_{2} \ln (\text { srlpca })_{s t}+\beta_{s} \ln (s f a c a)_{s t}+\beta_{t} \ln (i a)_{s t}+\beta_{s} \ln (f c c a)_{s t}+\beta_{6} \ln (\text { ralcca })_{s t}+\beta_{7} \ln (v p r c)_{s t}+\beta_{s} \ln (\text { vamaxtst })_{s t}+\beta_{s}$ $\ln \left(\right.$ vamaxtgt $_{s t}+\beta_{10} \ln \left(\right.$ vamaxtht $_{s t}+\beta_{11} \ln \left(\right.$ vamintst $_{s t}+\beta_{12} \ln \left(\right.$ vamintgt $_{s t}+\beta_{1 s} \ln \left(\right.$ vamintht $_{s t}+\beta_{14} \ln (\text { vapcpst })_{s t}+\beta_{15} \ln (\text { vapcpgt })_{s t}$ $+\beta_{16} \ln (\text { vapcpht })_{s t}+\beta_{17} \ln (\operatorname{cvdapcp})_{s t}+\beta_{1 s} \ln (\text { cvdamint })_{s t}+\beta_{19} \ln \left(\right.$ cvdamaxt $_{s t}+\left(v_{s t}-u_{s t}\right)$

Here, $t p$-Production (in 000 Tonne) of respective crop in state $(s)$ in time $(t)$; $\ln$-Natural logarithms of associated variables; as-Area sown (in $000 \mathrm{Ha}$ ); srlpca- Share of rural literature population with cropped area (in Number); sfaca-Share of forest area with cropped area (in $000 \mathrm{Ha}$ ); $i a$ - Irrigated area (in $000 \mathrm{Ha}$ ); $f c c a$-Fertilizer consumption on cropped area (in ooo Tonnes); ralcca- Share of rural agricultural labour and cultivator with cropped area (in Number); vprc-Value of production of respective crop at constant prices of 1993-94 (in INR); vamaxtst, vamaxtgt and vamaxtht (in \%)-Variability in maximum tempereture during sowing time, growing time and harvesting time respectively; vamintst, vamintgt and vamintht (in \%)-Variability in minimum temperature during sowing time, growing time and harvesting time respectively; vapcpst, vapcpgt and vapcpht (in \%)-Variability in precipitation during sowing time growing time, growing time and harvesting time respectively; cvdapcp, cvdamint and cvdamaxt (in \%)-Coefficient variation in daily precipitation, minimum tempereture and maximum temperature respectively during crop period. $\beta_{0}$ is the constant coefficient; $\beta_{1,} \ldots \beta_{19}$ are the regression coefficients of associated explanatory variables; $v_{s t}$ and $u_{s}$ are the symmetric error term and non-negative random variable respectively in the Equation 4 . 
Also, land productivity (yield) or production per hectare land of cash crops was used as depended variables and regressed with climatic and non-climatic factors. For this, following functional form of empirical model was used $[9,40]$ :

$\ln (l p)_{s t}=\alpha_{o}+\alpha_{1} \ln (a s)_{s t}+\alpha_{2} \ln (\text { srlpca })_{s t}+\alpha_{s} \ln (s f a c a)_{s t}+\alpha_{t} \ln (i a)_{s t}+\alpha_{s} \ln (f c c a)_{s t}+\alpha_{6} \ln (\text { ralcca })_{s t}+\alpha_{z} \ln (v p r c)_{s t}+\alpha_{s} \ln (\text { vamaxtst })_{s t}+\alpha_{s}$ $\ln \left(\right.$ vamaxtgt $_{s t}+\alpha_{10} \ln \left(\right.$ vamaxtht $_{)_{s t}}+\alpha_{11} \ln (\text { vamintst })_{s t}+\alpha_{12} \ln \left(\right.$ vamintgt $_{)_{t t}}+\alpha_{13} \ln \left(\right.$ vamintht $_{s t}+\alpha_{14} \ln (\text { vapcpst })_{s t}+\alpha_{15} \ln (\text { vapcpgt })_{s t}$ $+\alpha_{16} \ln \left(\right.$ vapcpht $_{s t}+\alpha_{17} \ln (\text { cvdapcp })_{s t}+\alpha_{1 s} \ln (\text { cvdamint })_{s t}+\alpha_{19} \ln \left(\right.$ cvdamaxt $_{s t}+\left(v_{s t}-u_{s t}\right)$

Here, $l p$-Land productivity (yield) of respective crop in state $(s)$ in time $(t)$; $l n$-Natural logarithms of associated variables. The detail description of all explanatory variables are presented in earlier Equation $5 . \alpha_{\circ}$ is the constant coefficient; $\alpha_{1, \ldots} \alpha_{19}$ are the regression coefficients of corresponding explanatory variables.

The present study assess the impact of climate variability on cropped area of cash crops, therefore area sown of respective crop is considered as dependent variables and regressed with climatic and non-climatic factors. For this, the proposed model accept that area sown of a crop get impacted due to variability in climatic factors in sowing time only [9, 40]. It also considered that area sown of a crop has a functional relationship with srlpca, sfaca, ia, ralcca, vprc, vamaxtst, vamintst, vapcpst, cvdapcpst, cvdamintst and cvdamaxtst. After converting it into C-D production functional model, said relationship can be written in following form [9, 40]:

$\ln (a s)_{s t}=\gamma_{0}+\gamma_{1} \ln (\operatorname{srlpca})_{s t}+\gamma_{2} \ln (\text { sfaca })_{s t}+\gamma_{3} \ln (i a)_{s t}+\gamma_{4} \ln (\text { ralcca })_{s t}+\gamma_{5} \ln (\text { vprc })_{s t}+\gamma_{6} \ln \left(\right.$ vamaxtst $_{s t}+\gamma_{7} \ln (\text { vamintst })_{s t}+\gamma_{8}$ $\ln (\text { vapcpst })_{s t}+\gamma_{9} \ln (\text { cvdapcpst })_{s t}+\gamma_{10} \ln (\text { cvdamintst })_{s t}+\gamma_{11} \ln (\text { cvdamaxtst })_{s t}+\left(v_{s t}-u_{s t}\right)$

Here, as-Area sown of respective crop in state $(s)$ in time $(t)$; cvdapcpst, cvdamintst and cvdamaxtst (in \%)Coefficient variation in daily precipitation, minimum tempereture and maximum temperature respectively during sowing time. $\gamma_{0}$ is the constant coefficient; $\gamma_{1, \ldots} \gamma_{11}$ are the regression coefficients of corresponding independent variables in Equation 6. Signification on other variables has presented in Equation 5. Regression coefficients and technical efficiencies of yield, production and area sown functions of all crops are estimated through STATA statistical software.

\subsection{Consistency and Viability of Dependent and Explanatory Variables}

Dependent Variables: The present study was used production (tp) (in 000 tonne), yield $(L P)$ (in $\mathrm{Kg} / \mathrm{Ha}$ ) and area sown (as) (in $000 \mathrm{Ha}$ ) as a dependent variables in three different types of empirical exercises [1, 3, 8, 9, 41] .

Non-climatic and Control Variables: Area sown (as) (in $000 \mathrm{Ha}$ ), irrigated area (ia) (in OOO Ha), fertilizer consumption on cropped area $(f c c a)$ (in tonne), share of rural literature population with cropped area $(s r l p c a)$ (in number), share of rural agricultural labour and cultivator with cropped area (ralcca) (in number) and value of production of respective crop $(v p c c)$ (in Rs) are considered as explanatory variables [1, 3, 4, 9, 10, 41] .

Ecological Factor: Forest area is an important factor to maintain sustainability in environmental factors, therefore it might be ecosystem adaption based techniques to mitigate the negative consequences on climate change in crop farming. Hence, share of forest area with cropped area (sfaca) (in $000 \mathrm{Ha}$ ) was used to capture the impact of ecological factor on cash crop farming $[1,41]$.

Variability in Climatic Factors: Maximum tempereture, minimum tempereture and precipitation are the crucial weather factors which are significantly associated with growth, development and productivity of crops. So these factors are considered as a climatic factors $[1,5,8,10,19,25,26,41]$. To estimate the variability in climatic factors, the original value of a particular climatic factor is subtracted from the mean value of respective climatic factor for time period 1971-2014. Then, square root of this climatic factor is used to capture the climatic variability impact on production, productivity (yield) and cropped area of cash crops [9, 41] . Hence, climate variability in each factor is estimated as:

$$
\text { Variability }=\sqrt{[(X s t-X)]^{2}}
$$

Here, $X_{i t}$ is original value of climatic factor in state $(s)$ and year $t$; and $X$ is mean value of particular climatic factor for time period 1971-2014 in Equation 7 [9, 38]. Coefficient variation is used to assess the impact of daily variation in climatic factor on production, yield and cropped area cash crops [9, 10, 14] .

\subsection{Limitation of the Study}

Solar radiation, sunshine, wind speed, hail storm, humidity, fog, $\mathrm{CO}_{2}$ concentration, soil moisture and other weather patterns, which directly or indirectly affect the crop production, yield and cropped area of crops. Though, these variables are not included in this study. Furthermore, it also assumes that all varieties of a crop is similarly get affected due to climate change, while farmers are cultivating various varieties of a crop. Also, it accepts that a particular state lies in the same agro-ecological zone, while India is divided in 15 broad agro-climatic zones with 127 sub agro-climatic zones. Many states (e.g. Uttar Pradesh, Madhya Pradesh, Bihar, Punjab, Haryana, Orissa, Rajasthan etc.) are divided in various agro-ecological zones. However, this study could not capture the zone-wise effects on crop productivity, production and cropped area of crops.

\section{Statistical Inferences on Regression Results \\ 6.1. Association of Crops Production and Climatic and Non-climatic Factors}

Regression coefficients of climatic and non-climatic factors in production function of cash crops are estimated through time-invariant regression model. Impact of climatic and non-climatic factors on production of potato, cotton, groundnut and sesame crops are given in Equations 8, 9, 10 and 11 respectively. Regression coefficients of area sown with production of all crops are found positive and statistically significant. Thus, production of these crops have a high potential to be increased as area sown increases under [9]. Literate population have a lower 
interest in cultivation as compared to unskilled labours. So, rural literate population have a negative association with crop production. Forest area would be useful to mitigate the adverse effect of climate change in potato and groundnut farming [1,38]. Conversely, forest area have a negative implication on cotton and sesame crop farming. Irrigated area have a higher yielding capacity than non-irrigated area [1, 3, 4, 6, 7, 9, 14]. Thus, irrigated area have positive association with production of cotton and groundnut crops, it imply that production of these crops would be increased as irrigated area increases.

Extensive fertilizer application in cultivation, contribute high GHGs emission in atmosphere, thus it has a negative impact on environmental factors [42]. ${ }^{1}$ Thus, fertilizer application may be significant driver to increase variability in climatic factors. Subsequently, fertilizer application have a negative impact on crop production [1, 3, 4, 6, 7, 9, 14, 27]. Estimates specify that fertilizer consumption on cropped area have a negative impact on production of potato, cotton, groundnut and sesame crops. Application of agricultural labour and cultivator show positive impact on production of all cash crops. Estimates suggest that production would improve as utilization of agricultural labour and cultivator in cash crop farming. As Indian farmers are small and marginal who have farm size with less than 1 acre in which mechanization may be costly. Thus, application of human skill would be important to increase crop production. Appropriate price of crop is useful to increase crop production as farmer gives more preference to those crops that give them greater financial benefits [27]. It also increases the decision power of farmers to choose an appropriate crop for cultivation. Value of production is a crucial factor to increase the farmer's consciousness to grow a specific cash crop. It improves farmer's economic capacity to use another inputs like organic fertilizer, pesticides, better quality of seed, advance technology and better irrigation in cultivation. Thus, value of production have a positive impact on production of all crops.

Few climatic factors have a statistically significant impact on production of cash crops. Maximum temperature during sowing time is appeared negative impact on production of potato and cotton crops. Estimates can be interpreted that germination of these crops decrease as variability in maximum temperature during sowing time, therefore production of these crops would decline. Variability in maximum temperature during growing time have a negative impact on production of potato and cotton crops [9, 15, 20]. Crop production of potato and cotton crops in harvesting time is also negatively impacted due to increase in maximum temperature during harvesting time. Minimum temperature during growing period have a positive and negative impact on production of cash crops. Estimates specify that minimum temperature during sowing time have a negative impact on potato and groundnut crops. It recommended that output of these crop grow in soil, therefore these crops require moderate minimum temperature during sowing, growing and harvesting time. Cotton and sesame crops get benefit due to increase in variability in minimum temperature during sowing time. Minimum temperature during growing time is seen negative impact on productivity of undertaken cash crops. Precipitation during sowing and harvesting time have a negative impact on production of cash crops. Estimates are consistent with earlier studies which argued that change in rainfall pattern have a negative impact on crop productivity [1, 6, 10, 14, 23, 27]. Coefficient variation in daily precipitation also show negative impact on production of cash crops. Coefficient variation in daily maximum and minimum temperature have a positive and negative impact on production of these crops.

${ }_{\text {Potato }} \ln (t p)_{s t}=-3.8643^{*}+0.7621^{*} \ln (\text { as })_{s t}-0.5505^{*} \ln (\operatorname{srlpca})_{s t}+0.0357 \ln (\text { sfaca })_{s t}-0.0485 \ln (\text { ia })_{s t}-0.1503^{*} \ln \left(f_{c c a}\right)_{s t}+0.3748^{*}$ $\ln (\text { ralcca })_{s t}+0.5547^{*} \ln (\text { vprc })_{s t}-0.0049 \ln \left(\right.$ vamaxtst $_{s t}-0.00156 \ln \left(\right.$ vamaxtgt $_{s t}-0.0059 \ln (\text { vamaxtht })_{s t}-0.0045 \ln (\text { vamintst })_{s t}-$

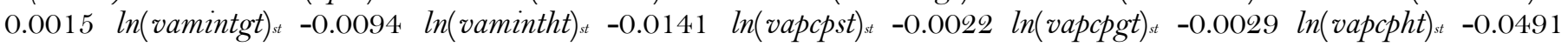
$\ln (\text { cvdapcp })_{s t}+0.0688 \ln (\text { cvdamint })_{s t}+0.0046 \ln (\text { cvdamaxt })_{s t}+\left(v_{s t}-u_{s t}\right) \quad\left[(N=578) \quad\left(\right.\right.$ Wald $\quad$ Chi $\left.i^{2}=6858.73^{*}\right) \quad(\log$ Likelihood $=-14.8610)$

cotton $\ln (t p)_{s t}=-7.4639 *+0.4845^{*} \ln (a s)_{s t}-0.6311^{*} \ln (\text { srlpca })_{s t}-0.0944^{*} * \ln (\text { sfaca })_{s t}+0.0547 * * * \ln (\text { ia })_{s t}-0.1231^{*} \ln (\text { fcca })_{s t}$ $+0.7567^{*} \ln (\text { ralcca })_{s t}+0.5670^{*} \ln (\text { vprc })_{s t}-0.0072 \ln (\text { vamaxtst })_{s t}-0.0189^{*} * * \ln (\text { vamaxtgt })_{s t}-0.0036 \ln (\text { vamaxtht })_{s t}+0.0025$ $\ln (\text { vamintst })_{s t}-0.0050 \ln (\text { vamintgt })_{s t}+0.0010 \ln (\text { vamintht })_{s t}-0.0004 \ln (\text { vapcpst })_{s t}+0.0145 \ln (\text { vapcpgt })_{s t}-0.0039 \ln (\text { vapcpht })_{s t}$ $+0.2088^{*} \ln (\text { cvdapcp })_{s t}-0.1824^{*} * \ln (\text { cvdamint })_{s t}+0.0374 \ln (\text { cvdamaxt })_{s t}+\left(v_{s t}-u_{s t}\right)\left[(N=583)\left(\right.\right.$ Wald Chi $\left.^{2}=6871.17^{*}\right)(\mathrm{Log}$ Likelihood $=-66.9939)]$

Groundnut $\ln (t p)_{s t}=-2.1741^{*}+1.0863^{*} \ln (a s)_{s t}-0.6311^{*} \ln (\text { srlpca })_{s t}+0.0770^{*} \ln (\text { sfaca })_{s t}+0.0676^{* *} \ln (\text { ia })_{s t}-0.2156^{*} \ln \left(f_{c c a}\right)_{s t}$ $+0.1982 \ln (\text { ralcca })_{s t}+0.5730^{*} \ln (\text { vprc })_{s t}+0.0128 \ln (\text { vamaxtst })_{s t}-0.0096 \ln (\text { vamaxtgt })_{s t}+0.0166^{*} * * \ln (\text { vamaxtht })_{s t}-0.0069$ $\ln (\text { vamintst })_{s t}-0.0066 \ln (\text { vamintgt })_{s t}-0.0006 \ln \left(\right.$ vamintht $_{s t}-0.0046 \ln (\text { vapcpst })_{s t}-0.0019 \ln (\text { vapcpgt })_{s t}-0.0065 \ln (\text { vapcpht })_{s t}-$ $0.1580^{*} * \ln (\text { cvdapcp })_{s t}+0.0211 \ln (\text { cvdamint })_{s t}-0.0384 \ln (\text { cvdamaxt })_{s t}+\left(v_{s t}-u_{s t}\right)\left[(N=581)\left(\right.\right.$ Wald Chi $\left.^{2}=13115.87^{*}\right)(\mathrm{Log}$ Likelihood $=-62.3242)]$

Sesame $\ln (t p)_{s t}=-3.1582^{*}+1.1245^{*} \ln (a s)_{s t}-0.5765^{*} \ln (\operatorname{srlpca})_{s t}+-0.0332 \ln (\operatorname{sfaca})_{s t}-0.0333 \quad \ln (\text { ia })_{s t}-0.2467^{*} \quad \ln \left(\right.$ fcca $_{s t}$ $+0.2625^{*} \ln (\text { ralcca })_{s t}+0.5340^{*} \ln (\text { vprc })_{s t}+0.0083 \ln \left(\right.$ vamaxtst $_{s t}-0.0019 \ln (\text { vamaxtgt })_{s t}-0.0028 \ln (\text { vamaxtht })_{s t}+0.0066$ $\ln (\text { vamintst })_{s t}-0.0145^{*} \ln (\text { vamintgt })_{s t}-0.0111 \ln \left(\right.$ vamintht $_{s t}-0.0039 \ln (\text { vapcpst })_{s t}-0.0059 \ln (\text { vapcpgt })_{s t}-0.0049 \ln (\text { vapcpht })_{s t}-$ $0.1682^{*} \ln (\text { cvdapcp })_{s t}+0.0584 \ln (\text { cvdamint })_{s t} 0.0864 \ln (\text { cvdamaxt })_{s t}+\left(v_{s t}-u_{s t}\right)\left[(N=626)\left(\right.\right.$ Wald Chi $\left.=6699.65^{*}\right)(\log$ Likelihood $=-71.4120)]$

\subsection{Association of Yield of Crops with Climatic and Non-climatic Factors}

Regression results which estimate the impact of climatic and non-climatic factors on yield of cash crops are given in Equation 12, 13, 14 and 15. Area sown is an important factor to decide output per hectare land and yield is negatively impacted due to increase in cropped area of cash crops [7, 43]. It has observed that yield have a nonlinear relationship with cropped area of cash crops [9, 43]. So, yield of potato, cotton and sesame crops have a negative associated with area sown. Yield of cash crops have a negative relationship with rural literate population. It may be due to that literate population have an insignificant contribution in farming. Regression coefficient of forest area with cropped area of potato and groundnut crops are positive, which imply that forest area might be useful to increase yield of potato and groundnut crops [1,38].

${ }^{1}$ http://www.epa.gov/climatechange/science/causes.html. 
Irrigated area would be useful to increase yield of cotton and groundnut crops, while yield of potato and sesame crops are negatively associated with irrigated area $[1,6,9,10]$. Regression coefficient of fertilizer consumption with yield of cash crops are found negative, it imply that yield of these crops would be declined as fertilizer application increases. Agriculture labour and cultivators and monetary value of crops have a positive impact on yield of cash crops. Better return on production of cash crop is helpful to increase the economic capacity of farmers, therefore they would be in a better position to apply advance methods in cultivation. Consequently, yield of cash crop would be increased as return on per hectare land increases.

Few climatic factors have statistically significant impact on yield of cash crops. Maximum temperature, minimum temperature and precipitation have a negative impact on potato yield. Maximum temperature during all crop growth period have a negative impact on cotton yield, while, minimum temperature during sowing and growing time are positively associated with cotton yield. In contrary, cotton yield have a negative association with precipitation during sowing and harvesting time. Estimates also indicate that daily variation in climatic factors also show negative impact on cotton yield. As groundnut crop needs moderate minimum temperature during sowing, growing and harvesting time. Thus, any variability in minimum temperature would have a negative impact on growth and yield of groundnut crop. Groundnut crop requires less water as compared to other crops, thus increase in precipitation have a negative impact on groundnut yield. Sesame yield is negatively influenced due to variability in climatic factors during sowing, growing and harvesting time. Furthermore, estimates show that variability in climatic factors during sowing, growing and harvesting time have a negative impact on yield of potato, cotton, groundnut and sesame crops.

Potato $\ln (\operatorname{lp})_{s t}=3.0434^{*}-0.2379^{* *} \ln (a s)_{s t}-0.5505^{*} \ln (\text { srlpca })_{s t}+0.0357 \ln (s f a c a)_{s t}-0.0485 \ln (i a)_{s t}-0.15032^{*} \ln \left(f_{c c a}\right)_{s t}$ $+0.3748^{*} \ln (\text { ralcca })_{s t}+0.5547 * \ln (\text { vprc })_{s t}-0.0049 \ln (\text { vamaxtst })_{s t}-0.0016 \ln (\text { vamaxtgt })_{s t}-0.0059 \ln (\text { vamaxtht })_{s t}-0.0045$ $\ln (\text { vamintst })_{s t}-0.0015 \ln \left(\right.$ vamintgt $_{s t}-0.0094 \ln \left(\right.$ vamintht $_{s t}-0.0141 \ln (\text { vapcpst })_{s t}-0.0022 \ln (\text { vapcpgt })_{s t}-0.0029 \ln (\text { vapcpht })_{s t}-$ $0.0491 \ln (\text { cvdapcp })_{s t}+0.0688 \ln (\text { cvdamint })_{s t}+0.0046 \ln (\text { cvdamaxt })_{s t}+\left(v_{s t}-u_{s t}\right) \quad\left[(N=578)\left(\right.\right.$ Wald Chi $\left.^{2}=1304.91^{*}\right)(\log$ Likelihood $=-14.8654)]$

Cotton $\ln (\operatorname{lp})_{s t}=-2.3281^{*}-0.5155^{* * *} \ln (a s)_{s t}-0.6311^{*} \ln (\text { srlpca })_{s t}-0.0944^{* *} \ln (s f a c a)_{s t}+0.0548 * * * \ln (\text { ia })_{s t}-0.1231^{*} \ln \left(f_{c c a}\right)_{s t}$ $+0.7567 * \ln (\text { ralcca })_{s t}+0.5670^{*} \ln (v p r c)_{s t}-0.0072 \ln (\text { vamaxtst })_{s t}-0.0189^{*} * * \ln \left(\right.$ vamaxtgt $_{s t}-0.0036 \ln \left(\right.$ vamaxtht $_{s t}+0.0025$ $\ln (\text { vamintst })_{s t}-0.0050 \ln (\text { vamintgt })_{s t}+0.0010 \ln \left(\right.$ vamintht $_{s t}-0.0004 \ln (\text { vapcpst })_{s t}+0.0145 \ln (\text { vapcpgt })_{s t}-0.0039 \ln (\text { vapcpht })_{s t}$ $+0.2088^{*} * \ln (\text { cvdapcp })_{s t}-0.1824^{*} * \ln (\text { cvdamint })_{s t}+0.0373 \ln (\text { cvdamaxt })_{s t}+\left(v_{s t}-u_{s t}\right) \quad\left[(N=583)\left(\right.\right.$ Wald Chi $\left.^{2}=1435.51^{*}\right)$ $($ Log Likelihood $=-66.9969)$

Groundnut $\ln (l p)_{s t}=4.7359^{*}+0.087 \ln (a s)_{s t}-0.6313^{*} \ln (\operatorname{srlpca})_{s t}+0.0771^{*} \ln (\text { sfaca })_{s t}+0.0667^{*} * \ln (\text { ia })_{s t}-0.2151^{*} \quad \ln (f c c a)_{s t}$ $+0.1978^{*} \ln (\text { ralcca })_{s t}+0.5730^{*} \ln (\text { vprc })_{s t}+0.0128 \ln (\text { vamaxtst })_{s t}-0.0096 \ln \left(\right.$ vamaxtgt $_{s t}+0.0167^{*} * * \ln (\text { vamaxtht })_{s t}-0.0069$ $\ln (\text { vamintst })_{s t}-0.0067 \ln (\text { vamintgt })_{s t}-0.0006 \ln \left(\right.$ vamintht $_{s t}-0.0046 \ln (\text { vapcpst })_{s t}-0.0019 \ln (\text { vapcpgt })_{s t}-0.0065 \ln (\text { vapcpht })_{s t}-$ $0.1581^{*} \ln (c v d a p c p)_{s t}+0.0212 \ln (\text { cvdamint })_{s t}-0.0384 \ln (\text { cvdamaxt })_{s t}+\left(v_{s t}-u_{s t}\right) \quad\left[(N=581)\left(\right.\right.$ Wald Chi $\left.=2154.19^{*}\right)(\log$ Likelihood $=-62.3299)$

Sesame $\ln (l p)_{s t}=3.7526^{*}+0.1248^{*} * * \ln (a s)_{s t}-0.5762^{*} \ln (\operatorname{srlpca})_{s t}-0.0332 \ln (\text { sfaca })_{s t}-0.0331 \quad \ln (\text { ia })_{s t}-0.2467 * \quad \ln (f c c a)_{s t}$ $+0.2619^{*} \ln (\text { ralcca })_{s t}+0.5340^{*} \ln (\text { vprc })_{s t}+0.0083 \ln \left(\right.$ vamaxtst $_{s t}-0.0019 \ln \left(\right.$ vamaxtgt $_{s t}-0.0028 \ln (\text { vamaxtht })_{s t}+0.0066$ $\ln (\text { vamintst })_{s t}-0.0145^{*} * * \ln (\text { vamintgt })_{s t}-0.0111 \ln \left(\right.$ vamintht $_{s t}-0.0039 \ln (\text { vapcpst })_{s t}-0.0059 \ln (\text { vapcpgt })_{s t}-0.0049 \ln (\text { vapcpht })_{s t}$ $-0.1681^{*} \ln (\text { cvdapcp })_{s t}+0.0585 \ln (\text { cvdamint })_{s t}+0.0864 \ln (\text { cvdamaxt })_{s t}+\left(v_{s t}-u_{s t}\right) \quad\left[(N=626) \quad\left(\right.\right.$ Wald $\quad$ Chi $\left.i^{2}=1408.82^{*}\right)$ (Log Likelihood $=-71.4405)$

6.3. Association of Cropped Area of Crops with Climatic and Non-climatic Factors

Regression coefficients of area sown of cash crops with climatic and non-climatic factors are given in Equation 16, 17, 18 and 19. Estimates indicate that area sown are positively associated with rural literate population, forest area, irrigated area, and agricultural labour and cultivators. Irrigated area is a crucial determinant to increase areas sown, therefore it have positive impact on area sown. Hence, it is proposed that irrigated area would be useful to increase cropped area of cash crops [9, 38]. Agricultural labour and cultivators are useful to prepare land during sowing time of crops, thus agricultural labours and cultivators are positively associated with cropped area. Value of production of all crops have a negative impact on cropped area of respective crops. Monetary value of crop production would be useful to increase the farmer's economic capacity to buy new technology, high yielding varieties of seed, and other inputs, subsequently it may be useful to increase crop productivity. However, high cost of cultivation of cash crops may be another reason to reduce the farmer's consciousness to enlarge area under cash crops.

Regression coefficients of climatic variables shows that variability in maximum temperature and minimum tempereture during sowing time have a positive impact on area sown of potato, groundnut and sesame crops. Estimates infer that area sown positively reflects due to increase in maximum and minimum temperature during sowing time. Variability in precipitation have negative and statistically significant impact on cropped area of potato, groundnut and sesame crops. Also, variability in daily precipitation during sowing time is also negatively associated with area sown of cash crops. Cropped area of cotton crop is positively associated with precipitation. For positive association of precipitation in sowing time for this crop can be interpreted that the large cropped area of this crop comes under rainfed areas. While, variation in daily maximum and minimum temperature during sowing time show positive impact on cropped area of these crops.

\footnotetext{
${ }^{\text {Potato }} \ln (\text { as })_{s t}=-3.8397^{*}+0.1453^{*} \ln (\operatorname{srlpca})_{s t}+0.1041^{*} \ln (\text { sfaca })_{s t}+0.0633^{*} \ln (\mathrm{ia})_{s t}+0.6113^{*} \ln ($ ralcca $)-0.0380^{*} \ln (v p r c)_{s t}$ $+0.0033 \ln (\text { vamaxtst })_{s t}+0.0151^{*} \ln (\text { vamintst })_{s t}-0.0097^{*} * \ln (\text { vapcpst })_{s t}-0.0177 \ln (\text { cvdapcpst })_{s t}+0.0784^{*} * \ln (\text { cvdamintst })_{s t}$ $+0.1496^{*} \ln (\text { cvdamaxtst })_{s t}+\left(v_{s t}-u_{s t}\right)\left[(N=607)\left(\right.\right.$ Wald $\left.C h i^{2}=18488.19^{*}\right)(\log$ Likelihood $\left.=-489.2042)\right]$
} 
${ }^{C o t t o n} \ln (a s)_{s t}=-1.4850^{*}+0.1179^{*} \ln (\operatorname{srlpca})_{s t}+0.2678^{*} \ln (\operatorname{sfaca})_{s t}+0.0914^{*} \ln (\mathrm{ia})_{s t}+0.4983^{*} \ln ($ ralcca $)-0.0380^{*} \ln (v p r c)_{s t}-$ $0.0056 \ln \left(\right.$ vamaxtst $_{s t}-0.0022 \ln (\text { vamintst })_{s t}+0.0023 \ln (\text { vapcpst })_{s t}-0.1012^{*} * \ln (\text { cvdapcpst })_{s t}+0.0165 \ln (\text { cvdamintst })_{s t}$ $+0.1133^{* *} \ln (\text { cvdamaxtst })_{s t}+\left(v_{s t}-u_{s t}\right)\left[(N=603)\left(\right.\right.$ Wald $\left.C h i^{2}=19483.01^{*}\right)(\log$ Likelihood $\left.=-377.3423)\right]$

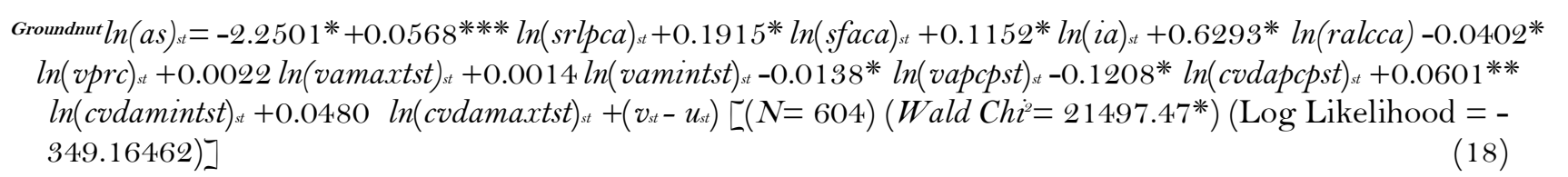

${ }^{\text {Sesame }} \ln (\text { as })_{s t}=-2.4808^{*}+0.0326^{*} * * \ln (\operatorname{srlpca})_{s t}+0.1551^{*} \ln (\mathrm{sfaca})_{s t}+0.0837^{*} \ln (\mathrm{ia})_{s t}+0.668 \mathrm{O}^{*} \ln (\mathrm{ralcca})-0.0256^{*} \ln (\text { vprc })_{s t}$ $+0.0003 \ln \left(\right.$ vamaxtst $_{s t}+0.0006 \ln \left(\right.$ vamintst $_{s t}+-0.0099^{*} * \ln (\text { vapcpst })_{s t}-0.1351^{*} \ln (\text { cvdapcpst })_{s t}+0.0468^{* * *} \ln (\text { cvdamintst })_{s t}$ $+0.0053 \ln (\text { cvdamaxtst })_{s t}+\left(v_{s t}-u_{s t}\right)\left[(N=649)\left(\right.\right.$ Wald $\left.C h i^{2}=15074.98^{*}\right)($ Log Likelihood $\left.=-420.6113)\right]$

\subsection{Explanation on Estimated Technical Efficiency of Cash Crops}

State-wise mean value of estimated technical efficiency (TE) during 1971-2014 for production, yield and area sown for potato, cotton, groundnut and sesame crops are presented in Figure 1, 2, 3 and 4. West Bengal have a highest TE (95\%) of production and yield of potato crop. Gujarat, Uttar Pradesh and Tamil Nadu have 86\%, 75\% and $71 \% \mathrm{TE}$ of production in potato crop Refer Figure 1. So, these states are able to produce better return in potato farming. It is observed that Rajasthan and Haryana have high efficiency to maintain the area sown under potato crop. Estimates conclude that all states have a high variation in technical efficiency to produce potato production and to maintain planting area under potato crop. Kerala is observed technically efficient state to produce optimum cotton production with TE of $90 \%$ Refer Figure 2. Other states have less than $50 \%$ TE of cotton production. Thus, these states are seen technically inefficient to produce cotton production and maintain higher yielding capacity. Haryana and Punjab are seemed most technically efficient states to utilize cropped area under cotton crop, while other states are appeared technically inefficient to increase or sustain planting area under this crop. Hence, it is suggested that other states need to apply technological advancement to increase technical efficiency of production and cropped area in cotton crop.

The value of TE is found 95\% for groundnut production and yield in Kerala, thus the state is technically efficient to produce optimum groundnut production Refer Figure 3 . Haryana has $87 \%$ TE of groundnut, imply that Haryana is second technically efficient state to produce groundnut output. Other states have value of TE less than $62 \%$, thus these states are technically inefficient in groundnut farming. Andhra Pradesh, Gujarat, Karnataka, Madhya Pradesh, Maharashtra and Rajasthan have less than 25\% value of TE, therefore these states are in poor position and unable to produce desire production of groundnut. Haryana have a $97 \%$ value of TE for cropped area, thus the state is in better position to utilize cropped area in groundnut farming, while Punjab is second technically efficient state to maintain cropped area under groundnut crop. Other states have a less than $90 \%$ value of TE, thus these states needed to increase technical efficiency in production and cropped area of groundnut crop.

Highest value of TE (94\%) for sesame production and yield in Kerala shows that this state is technically efficient to provide better return in sesame crop Refer Figure 4. Other states have low value of TE (less than 90\%), therefore these states are technically inefficient. There is needed to improve technical efficiency of sesame crop in these states. Haryana, Madhya Pradesh, Rajasthan, Uttar Pradesh, Maharashtra states have a less than $30 \%$ value of TE, thus these states are unable to produce desire output. Punjab and Haryana have $92 \%$ and $89 \%$ value of TE respectively for cropped area for sesame crop. So, these states have an ability to maintain cropped area under sesame crop. Remaining states have a low value of TE for area sown of sesame crops, thus these are technically ineffective to sustain cropped area under this crop.

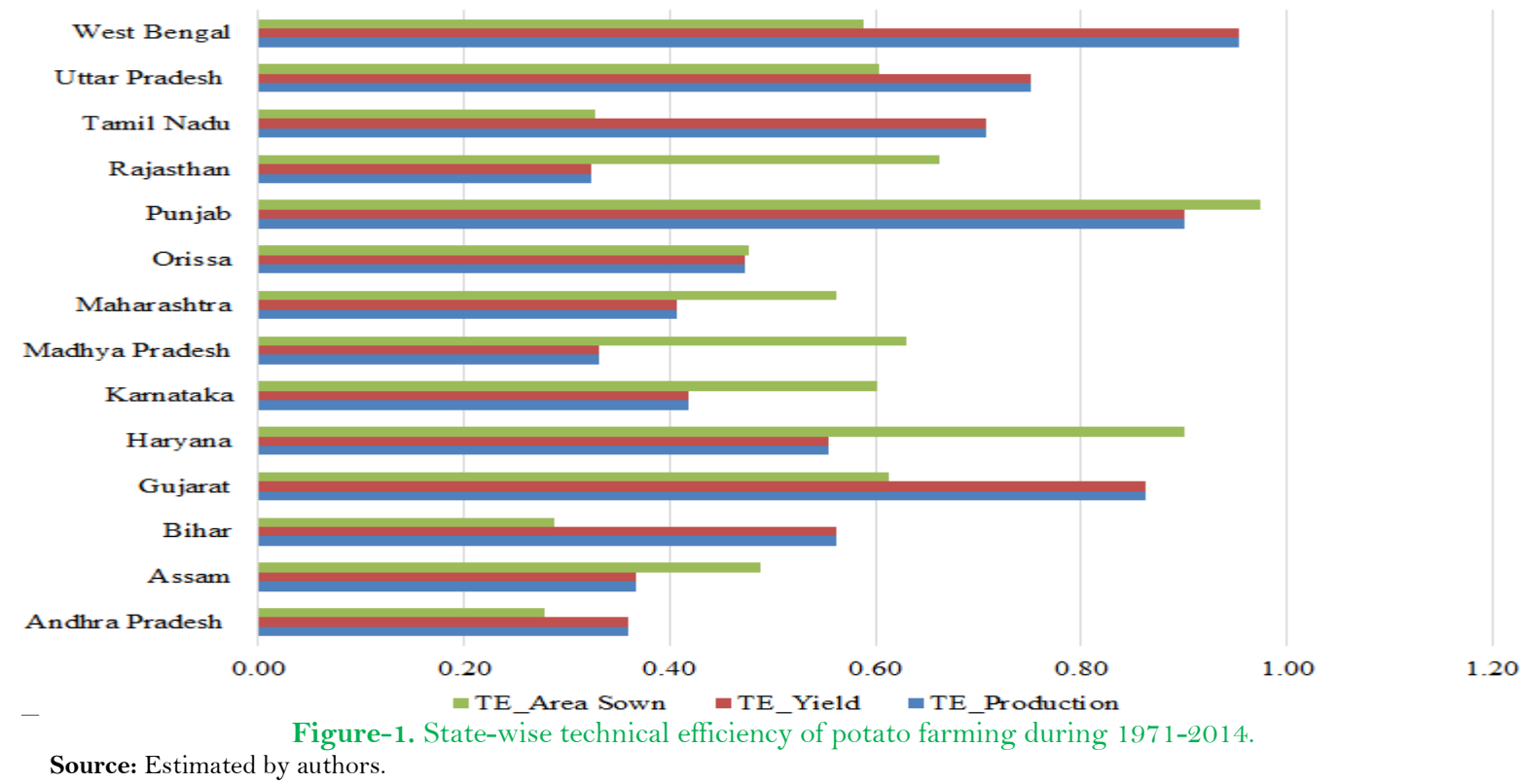




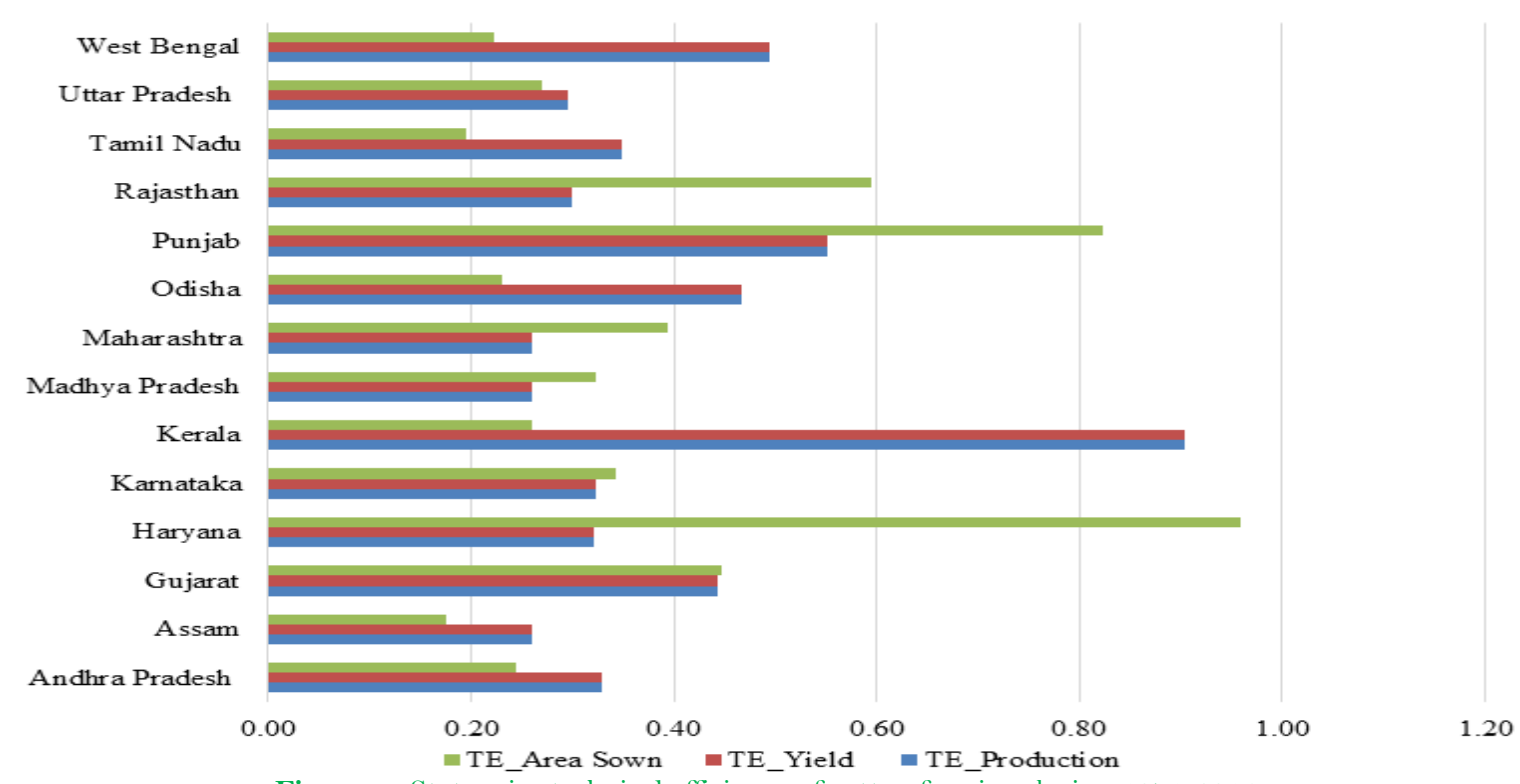

Source: Estimated by authors

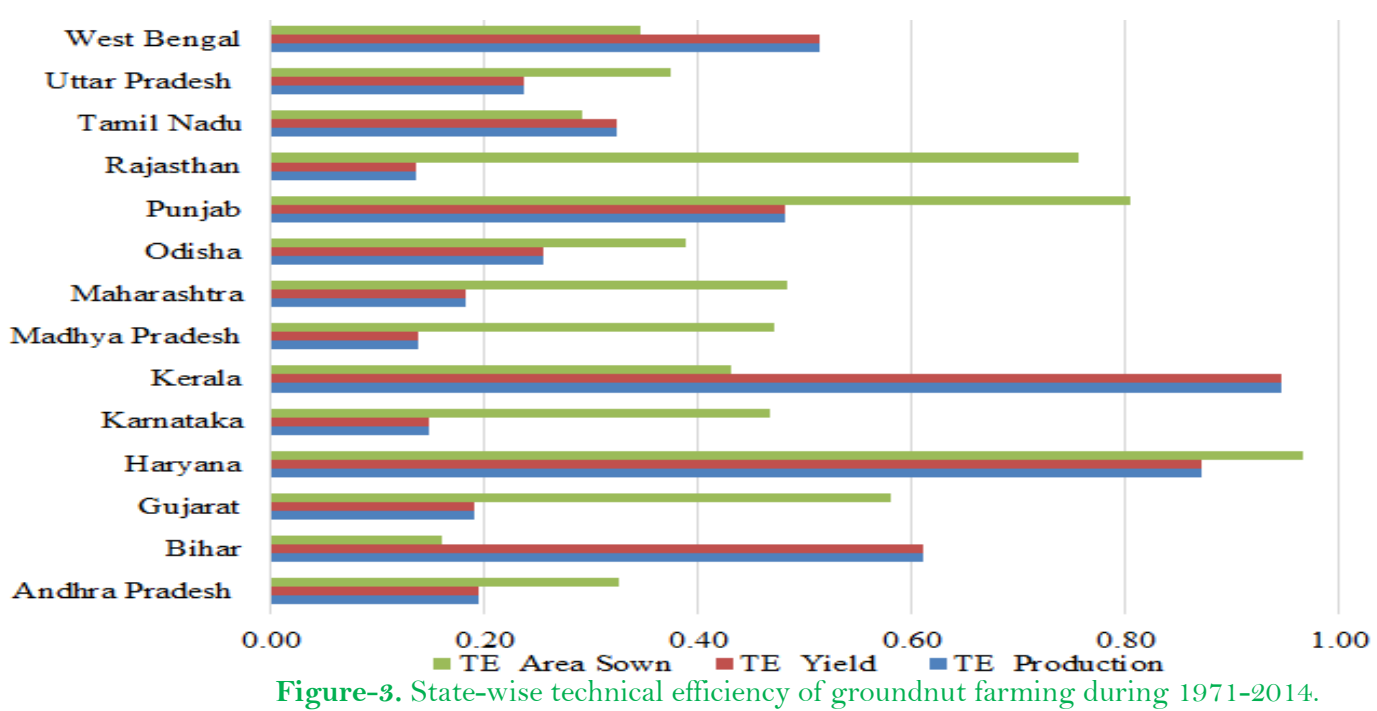

Source: Estimated by authors.

ure-3. State-wise technical efficiency of oround TE Production

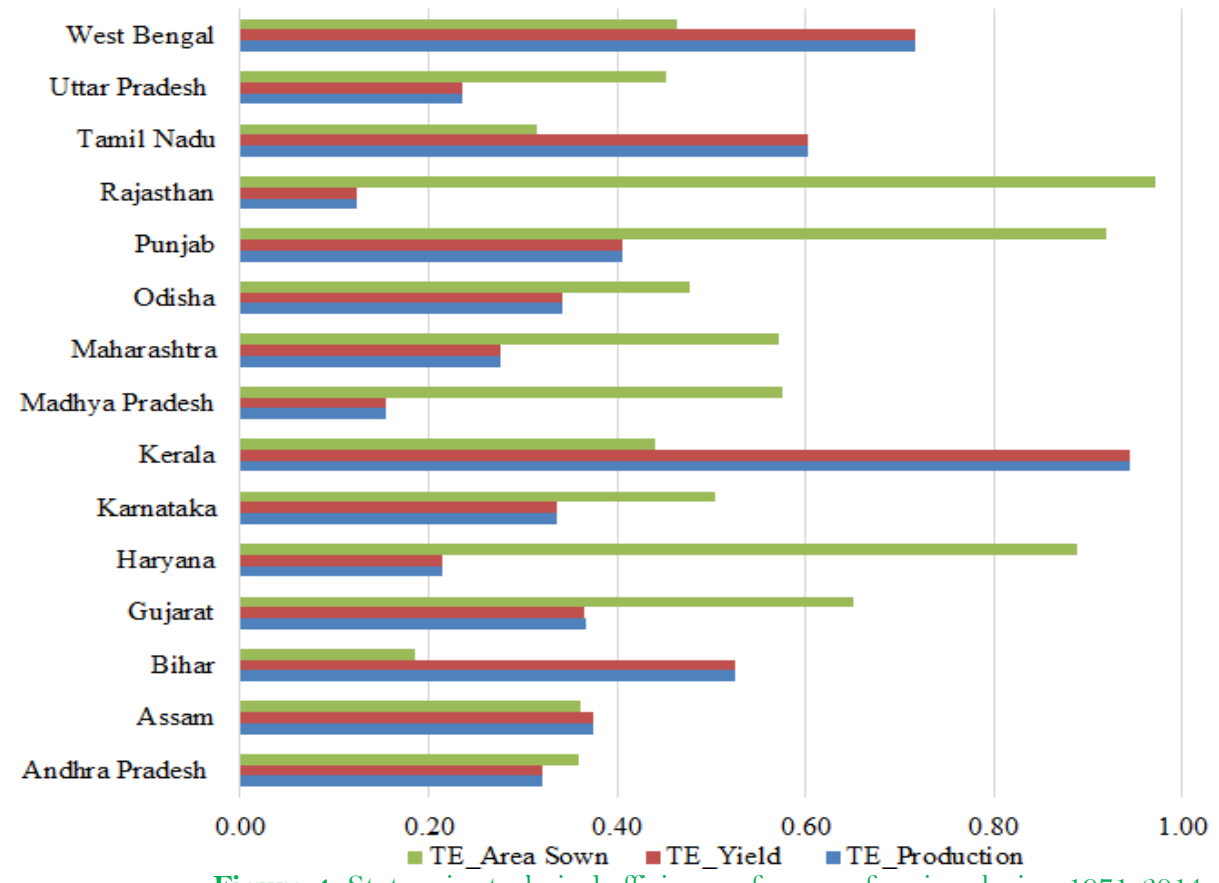

Source: Estimated by authors.

\section{Conclusion and Policy Implications}

This study is assessed the impact of climate variability on production, yield and cropped area of crucial commercial crops in India. For this, SFPFA model is employed using state-wise panel data during 1971-2014. Regression coefficients of climatic and non-climatic factors in proposed models are estimated through CobbDouglas production function (log-linear regression model). Accordingly, state-wise technical efficiency of production, yield and cropped area for each crop was estimated using time in-variant decay model under nonparametric condition. Empirical results show that variability in maximum temperature, minimum temperature and precipitation during sowing, growing and harvesting time have a negative and statistically significant impact on cropped area, production and yield of potato, cotton, groundnut and sesame crops. Here, it is concluded that cash 
crops farming is in stress due to variability in climatic factors in India. As potato, cotton, groundnut and sesame are crucial commercial crops which provide the raw material to agro-industries like textile, oilseed, and others. Therefore, agro-industries based on these crops would be in alarming position due to climate variability in India. Thus, it is advised that agro-industries are essential to take an effective action to mitigate the negative impact of climate change on cash crop farming. Otherwise, agro-industries would be in serious position in near future. It would also cause to decrease employment opportunities and production in industries, and supply of goods in domestic market.

Estimated state-wise technical efficiency of each crop infer that there is existence high variation in production activities of cash crops across Indian states. Most states are found technically inefficient to produce optimum production, which are also unable to use cropped area under cash crops efficiently. Kerala is not largely agrarian state of the county, despite that the state have highest technical efficiency in cotton, groundnut, and sesame crop production. West Bengal and Punjab are technically efficient states to produce optimum potato production. Haryana and Punjab are observed technically efficient states to better use of cropped area under potato, cotton, groundnut and sesame crops. Thus, it recommended that all states are required to improve their technical efficiency to get better returns in cash crop farming.

Non-climatic factors such as irrigated area, forest area and appropriate prices of crops would be helpful to mitigate the negative impact of climate variability in cash crop farming in India [41]. Also, change in plating time and crop varieties may be better adaption technique to reduce climate change impact on cash crop farming [2, 6, 9, 19, 29]. Moreover, modern breeding techniques of crops also would be favorable to mitigate the adverse effect of climate change in cultivation [5]. To sustain forest area, reforestation and water conservation techniques would be essential to mitigate the climate change impact in Indian cash crop farming in near future [10, 19]. Also, adoption of micro-irrigation techniques through sprinkler and drip irrigation may be useful to sustain water for irrigation in near future $[3,8,10,19,44]$. Application of renewable energy, green technology and suggested application of fertilizer may be valuable to reduce GHGs emission from agricultural activities [9, 10]. Extensive fertilizer application in cultivation would be caused to reduce soil nutrients contents. Thus, crop production and productivity has a tendency to be declined as extensive application of fertilizer in cultivation. As extensive utilization of fertilizer in cultivation contributes more GHGs emission in atmosphere, resulting it would turn as significant cause to increase more variability in climatic factors. So, recommended fertilizer application in cultivation would be helpful to adapt the climate change impact in cash crop farming. Also, application of technological change in cultivation have a better adaptability to resolve the climate change impact in farming $[8,9,14,17,19,23,25]$.

Moreover, implementation of drip-irrigation would be useful to maintain for soil quality and actual nutrition contents of soil [22, 44, 45]. Intercropping, mixed and multi-tier cropping pattern must be preferred by farmers to reduce climate change impact in cultivation $[10,19,22]$. To promote more organic farming may be advantageous to mitigate the adverse effect of climate change in agriculture [17, 45]. Irrigation facilities are useful to reduce the maximum temperature impact in cultivation $[3,5,8,10,19,44]$. Thus, water conservation technologies must be adopted by farmers to meet the irrigation requirement in agriculture, which would be useful to mitigate the negative consequences of climate change in cultivation in India [25]. There is essential to increase adoption of improved quality of seed, and to reduce contamination of soil and water surface to improve cash crops productivity [12]. Crop insurance policies would be useful to recover the cost of production for farmers, if crop production decreased or damaged due to climate variability $[1,3,8,17,26]$. For this, agro-industries desires to provide appropriate financial support to farmers to increase their consciousness to grow commercial and industrial crops like cotton, sugarcane, groundnut, potato, sesame and other crops. Government of India is also needs to provide financial support to agricultural scientists and researchers to do more research in agricultural related activities. Thereby, scientific research community would be in better position to develop drought resistant and high temperature tolerant crops to mitigate the negative effect of climate change in Indian cash crop farming [17, 19$]$.

\section{References}

[1] A. Kumar and P. Sharma, "Impact of climate variation on agricultural productivity and food security in rural India," Economics Discussion Papers, No. 2013-43, 2013a.

[2] K. Hebbar, M. Venugopalan, A. Prakash, and P. K. Aggarwal, "Simulating the impacts of climate change on cotton production in India," Climatic Change, vol. 118, pp. 701-713, 2013. Available at: https://doi.org/10.1007/s 10584-012-0673-4.

[3] A. Kumar and P. Sharma, "Climate change and sugarcane productivity in India: An econometric analysis," Journal of Social and Development Sciences, vol. 5, pp. 111-122, 2014.

[4] A. Kumar, P. Sharma, and S. K. Ambrammal, "Climatic effects on food grain productivity in India: A crop wise analysis," Journal of Studies in Dynamics and Change, vol. 1, pp. 38-48, 2014

[5] P. S. Birthal, N. D.S., S. Kumar, S. Aggarwal, A. Suresh, and M. T. Khan, "How sensitive is Indian agriculture to climate change?," Indian Journal of Agricultural Economics, vol. 69, pp. 475-487, $2014 \mathrm{~b}$.

[6] A. Kumar, P. Sharma, and S. K. Ambrammal, "Effects of climatic factors on productivity of cash crops in India: Evidence from state-wise panel data," Global Journal of Research in Social Sciences, vol. 1, pp. 9-18, $2015 \mathrm{a}$.

[7] A. Kumar, P. Sharma, and S. K. Ambrammal, "Climatic effects on sugarcane productivity in India: A stochastic production function application," International Journal of Economics and Business Research, vol. 10, pp. 179-203, 2015c.

[8] A. K. Singh, P. Sharma, and D. K. Singh, "Measuring the influence of weather variables on productivity of food-grain crops in India: An application of just \& pope's production technique," ABBS Management Business and Entrepreneurship Review, vol. 7, pp. 2946, 2016. Available at: https://doi.org/10.23874/amber/2016/v7/i2/121780.

[9] A. K. Singh, K. G. S. Narayanan, and P. Sharma, "Effect of climatic factors on cash crop farming in India: An application of CobbDouglas production function model," International Journal of Agricultural Resources, Governance and Ecology, vol. 13, pp. 175-210, 2017 a.

[10] A. Kumar, M. M. Ahmad, and P. Sharma, "Influence of climatic and non-climatic factors on sustainable food security in India: A statistical investigation," International Journal of Sustainable Agricultural Management and Informatics, vol. 3, pp. 1-30, 2017. Available at: https://doi.org/10.1504/ijsami.2017.10003789.

[11] A. Ramachandran, D. Praveen, R. Jaganathan, D. RajaLakshmi, and K. Palanivelu, "Spatiotemporal analysis of projected impacts of climate change on the major C3 and C4 crop yield under representative concentration pathway 4.5: Insight from the coasts of Tamil Nadu, South India," PloS One, vol. 12, pp. 1-19, 2017. Available at: https://doi.org/10.1371/journal.pone.0180706.

[12] B. P. Singh, V. K. Dua, P. M. Govindakrishnan, and S. Sharma, "Impact of climate change on potato," Climate-Resilient Horticulture: Adaptation and Mitigation Strategies, vol. 1, pp. 125-135, 2013.

[13] K. Ayyogari, S. P., and M. K. Pandit, "Impact of climate change on vegetable cultivation-A review," International Journal of Agriculture, Environment ङ Biotechnology, vol. 7, pp. 145-155, 2014. Available at: https://doi.org/10.5958/j.2230-732x.7.1.020. 
[14] A. Kumar, P. Sharma, and S. Joshi, "Effects of climatic factors on agricultural productivity in India: A state-wise panel data analysis," International Journal of Basic and Life Sciences, vol. 3, pp. 48-67, $2015 \mathrm{~b}$.

[15] M. K. Yadav, R. S. Singh, K. K. Singh, R. K. Mall, C. Patel, S. K. Yadav, and M. K. Singh, "Assessment of climate change on pulse, oilseed and vegetable crops at Varanasi, India," Journal of Agrometeorology, vol. 18, pp. 13-2 1, 2016.

[16] S. S. Hundal and P. Kaur, "Climatic variability and its impact on cereal productivity in Indian states," Current Science, vol. 42, pp. 506-512, 1996.

[17] K. Ashalatha, G. Munisamy, and A. Bhat, "Impact of climate change on rainfed agriculture in India: A case study of Dharwad," International Journal of Environmental Science and Development, vol. 3, pp. 368-371, 2012. Available at: https://doi.org/10.7763/ijesd.2012.v3.249.

[18] A. Kumar and P. Sharma, "Climate sensitivity and agriculture productivity in India: A crop-wise analysis," in Proceedings of the 7th Biennial Conference 2013 of the Indian Society for Ecological Economics (INSEE) on 'Global Change, Ecosystems, Sustainability', Organized at Tezpur University, Tezpur (Assam), 2013.

[19] P. S. Birthal, M. T. Khan, D. S. Negi, and S. Agarwal, "Impact of climate change on yields of majors food crops in India: Implications for food security," Agricultural Economics Research Review, vol. 27, pp. 145-155, $2014 \mathrm{a}$.

[20] R. Nath, P. Chakraborty, and A. Chakraborty, "Effect of climatic variation on yield of sesame (Sesamum indicum L.) at different dates of sowing," Journal of Agronomy and Crop Science, vol. 186, pp. 97-102, 2001. Available at: https://doi.org/10.1046/j.1439037x.2001.00456.x.

[21] G. Masters, P. Baker, and J. Flood, "Climate change and agricultural commodities," CABI Working Paper No. O2, 2010.

[22] K. Sankaranarayanan, C. Praharaj, P. Nalayini, K. Bandyopadhyay, and N. Gopalakrishnan, "Climate change and its impact on cotton (Gossypium sp.)," Indian Journal of Agricultural Sciences, vol. 80, pp. 561-575, 2010.

[23] A. Moorthy, W. Buermann, and D. Rajagopal, "The impact of climate change on crop yields in India." Available: http://hpccc.gov.in/PDF/Agriculture/Climate\%20Change\%20and\%20Crop\%20Yields\%20in\%20India.pdf, 2012.

[24] D. Deshmukh and H. Lunge, "Impact of global warming on rainfall, and cotton lint with vulnerability profiles of five districts in Vidarbha, India," International Journal of Scientific \& Technology Research, vol. 1, pp. 77-85, 2012.

[25] B. Raju, C. R. Rao, V. Rao, M. S. Rao, and M. Maheswari, "Effect of climate on productivity of pigeonpea and cotton in Andhra Pradesh-A panel data regression," Indian Journal of Dryland Agricultural Research and Developmen, vol. 29, pp. 06-10, 2014. Available at: https://doi.org/10.5958/2231-6701.2014.01187.7.

[26] H. Thakare, P. Shrivastava, and K. Bardhan, "Impact of weather parameters on cotton productivity at Surat (Gujarat), India," Journal of applied and Natural science, vol. 6, pp. 599-604, 2014. Available at: https://doi.org/10.31018/jans.v6i2.503.

[27] A. Kumar, P. Sharma, and S. Joshi, "Assessing the impacts of climate change on land productivity in Indian crop agriculture: An evidence from panel data analysis," Journal of Agricultural Science and Technology, vol. 18, pp. 1-13, 2016.

[28] A. Kumar and P. Sharma, "Impact of climate variability on land productivity in India: A panel data analysis," Journal Earth Science E Climate Change, vol. 4, pp. 0-1, $2013 \mathrm{~b}$.

[29] R. J. Hijmans, "The effect of climate change on global potato production," American Journal of Potato Research, vol. 80, pp. 271-280, 2003. Available at: https://doi.org/10.1007/bfo2855363.

[30] P. Singh, N. Singh, K. Boote, S. Nedumaran, K. Srinivas, and M. Bantilan, "Management options to increase groundnut productivity under climate change at selected sites in India," Journal of Agrometeorology, vol. 16, pp. 52-59, 2014.

[31] A. A. Girel, B. Dire, M. M. Iliya, and M. Salihu, "Stochastic frontier production function on the resource use efficiency of demand II crop farmers in Adamawa State, Nigeria," European Journal of Agricultural and Forestry Research, vol. 1, pp. 1-15, 2013.

[32] N. Hussain, S. Ali, N. Miraj, and M. Sajjad, "An estimation of technical efficiency of garlic production in Khyber Pakhtunkhwa Pakistan," International Journal of Food and Agricultural Economics, vol. 2, pp. 169-178, 2014.

[33] M. A. Hamjah, "Climatic effects on cotton and tea production in Bangladesh and measuring efficiency using multiple regression and stochastic frontier model respectively," Mathematical Theory and Modeling, vol. 4, pp. 86-98, 2014.

[34] J. Ng'ombe and T. Kalinda, "A stochastic frontier analysis of technical efficiency of maize production under minimum tillage in Zambia," Sustainable Agricultural Research, vol. 4, pp. 31-45, 2015. Available at: https://doi.org/10.5539/sar.v4n2p31.

[35] S. Kea, H. Li, and L. Pich, "An analysis of technical efficiency for household's rice production in Cambodia: A case study of three districts in Battambang Province," 2016.

[36] B. C. Okoye, A. Abass, B. Bachwenkizi, G. Asumugha, B. Alenkhe, R. Ranaivoson, R. Randrianarivelo, N. Rabemanantsoa, and I. Ralimanana, "Differentials in technical efficiency among smallholder cassava farmers in Central Madagascar: A Cobb Douglas stochastic frontier production approach," Cogent Economics ङ Finance, vol. 4, pp. 1-10, 2016. Available at: https://doi.org/10.1080/23322039.2016.1143345.

[37] A. Ali and A. U. Jan, "Analysis of technical efficiency of sugarcane crop in Khyber Pakhtunkhwa: A stochastic frontier approach," Sarhad Journal of Agriculture, vol. 33, pp. 69-79, 2017. Available at: https://doi.org/10.17582/journal.sja/2017.33.1.69.79.

[38] A. K. Sngh, M. M. Ahamd, and P. Sharma, "Association of state-wise food security index with climatic factors in India: Evidence from state-wise panel data," Journal of Global Agriculture and Ecology, vol. 6, pp. 196-205, 2017b.

[39] V. H. Long and M. Yabe, "The impact of environmental factors on the productivity and efficiency of rice production: A study in Vietnam’s red river delta," European Journal of Social Sciences, vol. 26, pp. 2 18-230, 2011.

[40] M. Amin, J. Zhang, and M. Yang, "Effects of climate change on the yield and cropping area of major food crops: A case of Bangladesh," Sustainability, vol. 7, pp. 898-915, 2015. Available at: https://doi.org/10.3390/su7010898.

[41] A. K. Singh, K. G. S. Narayanan, and P. Sharma, "Influence of climate variability on sugarcane farming in India: An empirical research. In Nandan Nawn and Joy Elamon (Eds)," in Proceedings of the 9th Biennial Conference 2017 of the Indian Society for Ecological Economics (INSEE) on "Sustainability, Institutions, Incentives: Voices, Policies and Commitments", Organized by Kerala Institute of Local Administration, Thrissur [November 8-10, 2017], Indian Society for Ecological Economics, New Delhi, 2018.

[42] S. Attri and L. Rathore, "Simulation of impact of projected climate change on wheat in India," International Journal of Climatology, vol. 23, pp. 693-705, 2003. Available at: https://doi.org/10.1002/joc.896.

[43] J. Cabas, A. Weersink, and E. Olale, "Crop yield response to economic, site and climatic variables," Climate Change, vol. 101, pp. 599-616, 2010. Available at: https://doi.org/10.1007/s 10584-009-9754-4.

[44] A. K. Singh and P. Sharma, "Implications of climatic and non-climatic variables on food security in developing economies: A conceptual review," MOJ Food Processing \& Technology, vol. 6, pp. 1-12, 2018. Available at: https://doi.org/10.15406/mojfpt.2018.06.00138.

[45] K. R. Kranthi, "Cotton in the climate trap," Cotton Statistics \& Neres, vol. 6, pp. 6-9, 2014. 